\section{B A Institute of \\ YK Business Administration \\ 六下 \\ Karachi \\ Leadership and Ideas for Tomorrow}

Business Review

Volume 7 Issue 2 July-December 2012

7-1-2012

\title{
Impact of adopting HRIS on three tiers of HRM: Evidence from developing economy
}

Irfan Saleem

University of Central Punjab, Lahore, Pakistan

Follow this and additional works at: https://ir.iba.edu.pk/businessreview

Part of the Economics Commons, and the Human Resources Management Commons

(c) (i)

This work is licensed under a Creative Commons Attribution 4.0 International License.

\section{Recommended Citation}

Saleem, I. (2012). Impact of adopting HRIS on three tiers of HRM: Evidence from developing economy. Business Review, 7(2), 96-105. Retrieved from https://doi.org/10.54784/1990-6587.1206

This article is brought to you by iRepository for open access under the Creative Commons Attribution 4.0 License and is available at https://ir.iba.edu.pk/businessreview/vol7/iss2/7. For more information, please contact irepository@iba.edu.pk. 


\title{
ARTICLE
}

\section{Impact of adopting HRIS on three tiers of HRM: Evidence from Developing Economy}

\author{
Irfan Saleem \\ University of Central Punjab, Lahore, Pakistan
}

\begin{abstract}
In information based economies, cross-sectional studies are needed to uncover missing linkage between Human Resource Management and Information Technology. Consequently Human Resource (HR) researchers and managers need to rethink about achieving organizational objectives with and through the people added by modernized technology in this information age. The main objective of this study is to identify the contribution of Human Resource Information System (HRIS) adoption impact on three tiers i.e. Operational, Functional and Strategic Human Resource Management (HRM). Findings show that that HRIS adoption significantly impacts HRM Operational Processes and moderately facilitates its Functional Processes and provides insignificant support for Strategic HRM Processes.
\end{abstract}

Key words: Human Resource Management (HRM) and Human resource Information System (HRIS),

\section{Introduction}

Rapid economic growth and increased competition attributes to multifarious business environment which has lead to exponential growth of technology applications in all areas of business including Human Resource Management (HRM). Consequently, this change has forced Human Resource professionals and researchers to rethink about achieving organizational objectives through adoption of modernized Information Systems (IS). Growing importance of HRM with increasing organizational size requires the maintenance of employee related data and generating appropriate HR reports enforcing organizations for adoption of computer based HRM systems (Tripathi, 2011). Although HRM (Absar and Mahmood, 2011) and Information Technology (IT) have drawn the attention of researchers (Saleem et al, 2011), industry and academia, yet linkage between the two disciplines is still at cutting edge and need more exploration (Mishra and Akman 2010) in developing economies like Pakistan. It has also been noticed that IS have been applied to HRM for decades, nonetheless way of using IS has improved dramatically (Zhang and Wang, 2006). Accordingly, HR professionals and executives need to use IS to help them meeting their organization's information (Teo et al, 2001) which in turn improves professional standing of HR professionals in the organizations of good repute (Hussain et al, 2007). 


\section{Literature Review}

Emergence in technology and telecommunications mandate the transformation of HRM (Cleland et al, 2000). HR professionals thus need to respond to changing business conditions by demonstration of new competencies (Ulrich et al, 2007) which enforces today's enterprise management to be digitized (Zhang and Wang, 2006). Human Resource Information System (HRIS) meet the needs of a number of organizational stakeholders including HR professionals, managers in functional areas and employees in general (Power, 2004) and provides the vital link between IT and HRM.

\section{Human Resource Information System}

HRIS software are application systems that collect data and produce information about the workforce of an organization to facilitate personnel control, planning, development, and forecasting (Romm, Pliskin \& Weber, 1995). HRIS package is designed to help organize the myriad of administrative and strategic variables of which the HR department is responsible (Van-der-Linden and Parker, 1998). HRIS is being used since many decades. Early example of the application of IT in HRM includes the development and use of optical scanning equipment (Cronin et al, 2006). However, in the present days, managers are using it for every business process to facilitate all stakeholders of company including HR. Resultantly IT usage in HRM is becoming critical (Shaw, 1994). HRIS has also been improved from simple Database Management Systems to more sophisticated web-based repository of organizational HR information to be used at all levels of organizations including first line, middle line, top line managers and executives. The bottom line of any comprehensive HRIS have to be the HR information validity, reliability and utility first and the automation of the process second (Kovach et al, 2002) that may be used for all organizational levels. Thus there is a great need to explore the adoption of HRIS at all three managerial levels, which is discussed in next Section in the light of historic studies.

\section{HRIS Role and three Tiers of HRM}

Researchers have agreed that HRIS has capabilities in shaping the integration between HRM and IT by supporting administration (Teo el al, 2007), planning (Hussain et al, 2007) and strategic decision-making (Johnston and Carrico, 1988; DeSanctis, 1986). Scholars have agreed on the fact that HRIS supports most of HR applications including Record Keeping (Ball, 2001), Recruitment \& Selection (Chapman and Webster, 2003), Compensation (Kanthawongs (2004), Training \& Development (Chan and Ngai, 2007). As HR Managers have to manage plethora of HR activities including recruiting \& selection, training, promoting \& demoting, and recordkeeping, therefore essential component in the success of managing HR data is HRIS (Hubbard et al, 1998) that functional HRIS must create an information system that enables an assimilation of policies and procedures used to manage the firm's human capital (Hendrickson, 2003).

Managers rely on capabilities of HRIS to provide superior HR data collection and analysis, for making decisions regarding performance appraisal, performance management and many other HRM processes. Thus HRIS should be introduced for automation of HR Department (Absar and Mahmood, 2011). However, important factors associated with the implementation of new HRIS as the conditions that support successful implementation for HR staff differ from those for line managers (Wilson-Evered and Härtel, 2009). Above discussion focuses this research to identify role that HRIS can play to support to HRM at 
three tiers including Operational, Functional and Strategic HRM Processes. In the view of last section following main proposition has been developed.

\section{Proposition: Adopting HRIS supports Three Tiers of HRM}

\section{HRIS Role for Operational HRM}

HRIS is adopted to automate HRM activities in order to obtain some general administrative routine purposes (Altarawneh and Al-Shqairat, 2010). Transaction processing layer of Management Information System in HR function deals with routine activities like attendance recording and payroll calculations also called operational HRM activities (Tripathi, 2011). IT is being used in HR Department for administrative purpose including employees record keeping, preparation of salaries and attendance record (Teo et al, 2001; DeSanctis, 1986). Additional HR functions that could be streamlined technology include selection (Davies and Calderón, 2005) whereas online recruitment has become popular tool of IT (Cronin et al, 2006). Thus HRIS can support to perform traditional activities and supports day to day functions of HRM at Operational Level which includes Record Keeping, Payroll Preparation and Recruitment \& Selection. Based on this section, following proposition has been developed.

\section{Proposition A1: HRIS Adoption supports Operational HRM Processes.}

\section{HRIS Role for Functional HRM}

Functional HRM includes Training Need Assessment (Absar and Mahmood, 2011), Performance Appraisal (Huselid and Becker, 2011) and Compensation Management (Chen et al, 2011). Chan and Ngai (2007) have observed that Web-based training has become prevalent in business organizations. The typical HRIS user is HR officer (middle level for functional usage) in HR department (Al-Shibly, 2011). It is also identified that HRIS supports training (Ball, 2001). HRIS is becoming important for modern organizations to manage human assets effectively (Troshani, Jerram and Hill, 2011). HRIS allows the HR staff to dedicate more time to strategic decision making and planning, which consequently provides more value to the organization to enhance its position (Shani and Tesone, 2010) and provide facilitation at Functional Level. Thus HRIS can facilitate to perform at functional HRM processes which includes Training Need Assessment, Performance Appraisal and Compensation Management. Based on this section, following proposition has been developed.

\section{Proposition A2: HRIS Adoption supports Functional HRM Processes.}

\section{HRIS Role for Strategic HRM}

Roles and responsibilities are being evolved of HR professionals from a traditional perspective to a new strategic perspective (Delorme and Arcand 2010). The strategic level of support of HRIS has also been identified (Hussain et al, 2007; Boateng, 2007). Strategic HRM Processes includes Employee Career Development (Zhou, Zhang \& MontoroSánche, 2011), Turnover Tracking Analysis (Hutchings et al, 2011), HR Planning (Absar and Mahmood, 2011) and Strategic HR Decision Making (Huselid and Becker, 2011). As human capital plays a larger role in competitive advantage, functional managers expect the HRIS to provide functionality to meet the unit's goals and objectives (Power 2004). Another study on adoption of HRIS reveals that top management support and HRIS expertise are positively related to the adoption of HRIS (Teo et al, 2007). Effect of HRIS on strategic decisions reveals that banks can use the HRIS in strategic decisions and thus 
HRIS generate business value (Rangriz et al, 2011). Role of IS in HRM show taking management decisions related to management function especially for the top management (Tripathi, 2011). Thus HRIS can facilitate to perform at Strategic HRM Processes which will include Employee Career Development, Turnover Tracking Analysis, HR Planning and Strategic HR Decision Making. Based on this section, following proposition has been developed.

\section{Proposition A3: HRIS Adoption supports Strategic HRM Processes.}

\section{Conceptual Framework}

Various research models can be used in HR research including Descriptive, Explosive, schematics and Mathematical models. For this research descriptive model is being used and illustrated below in Figure A. The support of this conceptual model has been described in the view of literature in previous section. In the light of literature review, the followings propositions have been developed. The HR researchers have named HRM as HR best Practices (Qureshi and Hijazi, 2010; Shahzad et al, 2008). In the light of proposition and literature review, the following conceptual framework has been developed.

Figure A: Conceptual Framework

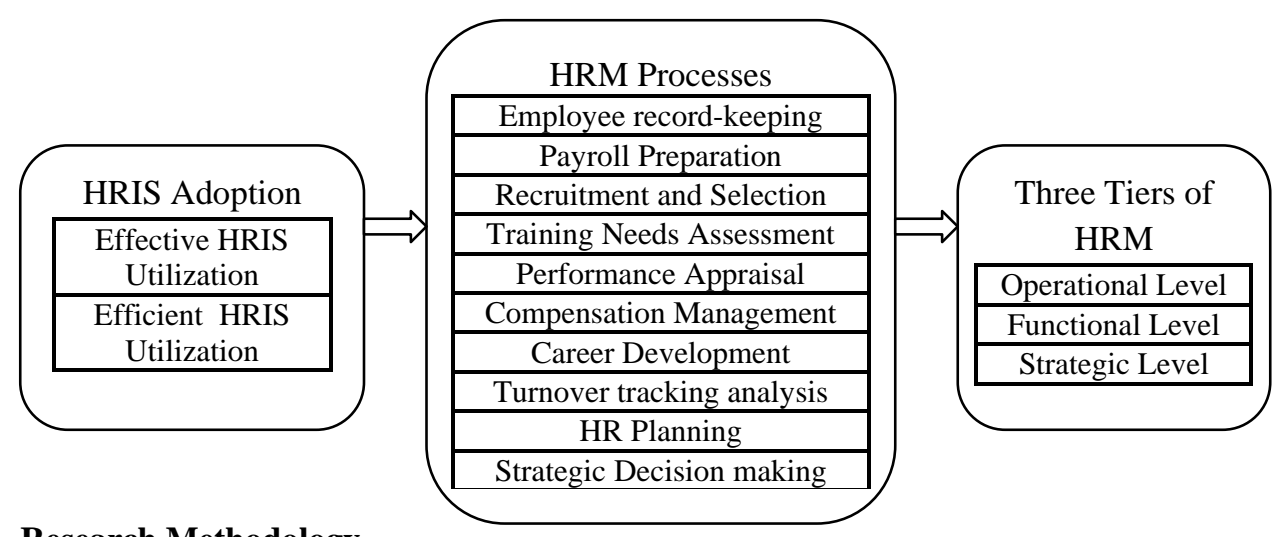

Research Methodology

This section focuses on population, sampling technique, instrumentation, data collection and findings. Research has mainly focused on service sector as population to find empirical evidence. Official websites have been used to retrieve most recent, complete and accurate list of organizations. "Snowball sampling" has been used for data collection with the reason that very few service sector organizations using HRIS and to make research process quicker. Aggregately 54 organizations responded with response rate of 51.43\% including 29 Adopters and 25 Non-Adopters of HRIS. For data collection, HR Managers and HRIS Experts were mailed questionnaires. The process of data collection took more than three months. Research analysis has used various statistical tools including Correlation and Regression analysis using SPSS 14 software package. Questionnaire for primary data collection was designed on a five point-Likert scale. To measure HRIS adoption Troshani, Jerram \& Hill (2011) study and Teo et al (2007) study has been utilized. Hussain et al (2007) and Kovach et al (2002) studies are used to find the impact of HRIS. To quantify HRM relationship with HRIS main input has been scanned 
from earlier research studies of Qureshi \& Hijazi (2010), Arthur \& Boyles (2007), Boateng (2007) and Johnston \& Carrico (1988).

\section{Research Findings}

This section will focus on correlation and regression analysis in order to empirically test the role and the impact of HRIS on three tiers of HRM.

\section{a) Correlation Analysis}

HRM Processes have been grouped under the guidance of previous studies including Operational, Functional and Strategic HRM. Refer to Table B, it is proved that HRIS highly support HRM Processes at operational level ( $\mathrm{r}=0.592)$. HRIS support moderately ( $r=0.255)$ Functional HRM Processes. However, the relationship is found to be positive and weak incase of Strategic HRM Processes(r=0.150). The combined effect is also significant $(\mathrm{r}=0.491)$

Table B: Correlation Matrix of HRIS Adoption and 3-Tiers of HRM

\begin{tabular}{|l|c|}
\hline \multicolumn{1}{|c|}{ 3-Tiers of HRM $\downarrow$} & HRIS Adoption \\
\hline Operational Level HRM & $0.592^{* *}$ \\
\hline Functional Level HRM & 0.255 \\
\hline Strategic Level HRM & 0.150 \\
\hline ** Correlation is significant at the 0.01 level (2-tailed). \\
\hline
\end{tabular}

\section{b) Impact Assessment of HRIS on three tiers of HRM}

This part of study will discuss three subsequent HRIS Adoption impacts including Operational, Functional and Strategic HRM in emerging service sector of developing economy.

\section{HRIS Impact on Operational HRM}

Proposition A1 HRIS Adoption supports Operational HRM Processes is accepted. Refer to Table C1 (Model E1), it is noted that correlation coefficient ( $\mathrm{r}=0.592)$ is highly significant explaining $32.5 \%$ variation $\left(\mathrm{r}^{2}=0.325\right)$. Regression equation is written as $\mathrm{Y}=$ $.675+0.886 \mathrm{X}$. Focusing on predictors, it is statistically proved that HRIS-Adoption (Beta/ $b=0.886)$ is highly significant $(\mathrm{p}=.001)$, and coefficient is positive indicating that HRIS-Adoption highly supports Operational HRM Processes.

Table C1: Regression coefficients for Operational HRM Processes

\begin{tabular}{|l|l|c|c|c|c|c|}
\hline & & $\begin{array}{c}\text { Unstandardized } \\
\text { Coefficients }\end{array}$ & & $\begin{array}{c}\text { Standardized } \\
\text { Coefficients }\end{array}$ & $\mathrm{t}$ & $\begin{array}{c}\text { P-Value/ } \\
\text { Sig. }\end{array}$ \\
\hline Model & & $\mathrm{B}$ & Std. Error & Beta & & \\
\hline E2 & (Constant) & .675 & 1.015 & & .665 & .051 \\
\hline & HRIS Adoption & .886 & .241 & .592 & 3.674 & .001 \\
\hline \multicolumn{6}{|c|}{ (a Dependent Variable: Operational Level HRM) } \\
\hline
\end{tabular}




\section{HRIS Impact on Functional HRM}

Proposition A2 HRIS Adoption supports Functional HRM processes is accepted. Refer to Table C2 (Model E2), it is shown that correlation coefficient $(r=0.255)$ is positive. Regression equation is written as $\mathrm{Y}=2.646+0.345 \mathrm{X}$. It is also identified that HRIS Adoption (Beta/ $b=0.255)$ is significant $(\mathrm{p}=.009)$, which indicates that HRIS Adoption is facilitating for Functional HRM Processes.

Table C2: Regression Coefficients for Functional HRM Processes

\begin{tabular}{|l|l|c|c|c|c|c|}
\hline & & $\begin{array}{c}\text { Unstandardized } \\
\text { Coefficients }\end{array}$ & $\begin{array}{c}\text { Standardized } \\
\text { Coefficients }\end{array}$ & $\mathrm{t}$ & $\begin{array}{c}\text { P-Value/ } \\
\text { Sig. }\end{array}$ \\
\hline Model & & $\mathrm{B}$ & Std. Error & Beta & & \\
\hline E2 & (Constant) & 2.646 & 1.101 & & 2.403 & .024 \\
\hline & HRIS Adoption & .345 & .261 & .255 & 1.320 & .009 \\
\hline \multicolumn{7}{|c|}{ (a Dependent Variable: Functional Level HRM) } \\
\hline
\end{tabular}

\section{HRIS Impact on Strategic HRM}

Proposition A3 HRIS Adoption supports Strategic Level HRM activities is rejected. Analysis shows that correlation coefficient $(\mathrm{r}=0.150)$ is insignificant (PValue $=0.454)$. However, coefficient is positive indicating that HRIS-Adoption can facilitate at strategic level of HRM Processes if more sophisticated HRIS are developed and better input is performed at operational level HRM.

Table C3: Regression Coefficients for Strategic HRM Processes

\begin{tabular}{|l|l|c|c|c|c|c|}
\hline & & $\begin{array}{c}\text { Unstandardized } \\
\text { Coefficients }\end{array}$ & & $\begin{array}{c}\text { Standardized } \\
\text { Coefficients }\end{array}$ & $\mathrm{t}$ & $\begin{array}{c}\text { P-Value/ } \\
\text { Sig. }\end{array}$ \\
\hline Model & & $\mathrm{B}$ & Std. Error & Beta & & \\
\hline E3 & (Constant) & 3.029 & 1.136 & & 2.666 & .013 \\
\hline & HRIS Adoption & .205 & .270 & .150 & .760 & .454 \\
\hline \multicolumn{7}{|c|}{ (a Dependent Variable: Strategic Level HRM) } \\
\hline
\end{tabular}

\section{Discussion}

Research statistically proves that support for HRIS towards HRM is significant. Referring to preceding studies, it is identified that study findings are consistent with many studies regarding HRIS support towards Operational HRM (Altarawneh and Al-Shqairat, 2010; Ball, 2001; Teo et al, 2001; DeSanctis, 1986). Notwithstanding, in-case of HRIS support towards Functional HRM, research results are partially consistent with various studies (Hussain et al, 2007; Davies and Calderón, 2005; Teo et al, 2001; DeSanctis, 1986). Nonetheless, research has found inconsistent results in-case HRIS support towards Strategic HRM with various studies (Hussain et al, 2007; Boateng, 2007; Davies and Calderón, 2005; Teo et al, 2001). The focus of study was to gain an insight into the current status of HRIS adoption in organizations in Pakistani service sector. Majority of 
the survey respondents indicated that HRIS was used mainly at Operational and Functional Level. It is therefore suggested that there may be more benefits in adopting HRIS for operational and functional level HR processes rather strategic level HR processes as companies may seek to gain efficiencies through reduction in staffing levels for routine administrative tasks.

\section{Future Research Directions}

Further research can be focused on barriers identification which is preventing the most of the organizations from adopting HRIS. Research is also needed to explore integration of HRIS at the strategic management level because it is quite relevant that HRIS can significantly improves the profitability of company by reducing monitoring and controlling the cost associated with HRM Processes. Finally studies can be conducted to measure HR Professionals standing in the organizations after HRIS adoption.

\section{References}

Absar M.M.N. and Mahmood M. (2011). New HRM Practices in the Public and Private Sector Industrial Enterprises of Bangladesh: A Comparative Assessment. International Review of Business Research Papers. 7(2): 118-136.

Al-Shibly H. (2011). Human Resources Information Systems success Assessment: An integrative model. Australian Journal of Basic and Applied Sciences. 5(5): 157-169.

Altarawneh I. and Al-Shqairat Z. (2010). Human Resource Information Systems in Jordanian Universities. International Journal of Business and Management. 5(10): 113127.

Anwar F., Saleem I., AND Zahid A. (2011), Significance of Total Quality Management in Organizational Performance: An Empirical Analysis from SMEs Sector. International Journal of Research in Commence, IT \& Management. 2 (1): 13-16.

Arthur B.J. and Boyles T. (2007) . Validating the human resource system structure: A levels-based strategic HRM approach. Human Resource Management Review. 17: 77-92.

Ball K.S. (2001). The use of human resource management systems: a survey. Personnel Review. 30 (6): 677-693.

Boateng A.A. (2007). The Role of Human Resource Information Systems (HRIS) in Strategic Human Resource Management (SHRM). Unpublished Dissertation, Master of Science in Accounting, Swedish School of Economics and Business Administration Sweden.

Chan S.C.H. and Ngai E.W.T. (2007). A qualitative study of information technology adoption: How ten organizations adopted Web-based training. Information Systems Journal. 17(3): 289-315. 
Chapman D. and Webster J. (2003). The use of technologies in the recruiting, screening, and selection processes for job candidates. International Journal of Selection and assessment. 2(3): 1-18.

Chen W.Y., Hsu B.F., Wang M.L., Lin Y.Y. (2011) .Fostering knowledge sharing through human resource management in R\&D teams. International Journal of Technology Management. 53(3): 309 - 330.

Cleland J., Pajo K. and Toulson P. (2000). Move it or lose it: an examination of the evolving role of the human resource professional in New Zealand. The International Journal of Human Resource Management. 11(1): 143-160.

Cronin B., Morath R., Curtin P. and Heil M. (2006). Public sector use of technology in managing human resources. Human Resource Management Review. 16: 416-430.

Davies S.A. and Calderón R.F. (2005). Integrating Handheld Computer Technology into HR Research and Practice. Torres-Coronas T. and Arias-Oliva M. (Eds.). In e-Human Resources Management: Managing Knowledge People (pp. 31-67.), Published in the USA and UK: Idea Group Publishing

Delorme M. and Arcand M. (2010). HRIS implementation and deployment: a conceptual framework of the new roles, responsibilities and competences for HR professionals. International Journal of Business Information Systems. 5(2): 148 - 161.

DeSanctis G. (1986). Human Resource Information Systems: A Current Assessment. MIS Quarterly. 10(1): 15-27.

Hendrickson A.R. (2003). Human Resources Information Systems: Backbone Technology of Contemporary Human Resources. Journal of Labor Research. 24(3): 382-394.

Hubbard J.C., Forcht K.A. and Thomas D.S. (1998). Human Resource Information Systems: An Overview of Current Ethical and Legal Issues. Journal of Business Ethics. 17: 1319-1323.

Huselid M.A. and Becker B.E. (2011).Walking New Avenues in Management Research Methods and Theories: Bridging Micro and Macro Domains. Journal of Management. 37 (2): 421-428.

Hussain Z., Wallace J. and Cornelius N.E. (2007). The use and impact of human resource information systems on human resource management professionals. Information and Management. 44: 74-89.

Hutchings K., De-Cieri H. and Shea T. (2011). Employee Attraction and Retention in the Australian Resources Sector. Journal of Industrial Relations. 53 (1): 83-101.

Johnston H.R. and Carrico S.R (1988). Developing capabilities to use information strategically. MIS Quarterly. 12(1): 37-50. 
Kanthawongs P. (2004). Does HRIS matter for HRM today? , BU Academic Review. 3(1): 104-109.

Kassim, N. M., Ramayah, T., \& Kurnia, S. (2012). Antecedents and outcomes of human resource information system (HRIS) use. International Journal of Productivity and Performance Management. 61(6): 603-623.

Kovach K.A., Hughes A.A., Fagan P. and Maggitti P.G. (2002). Administrative and strategic advantages of HRIS. Employment Relations Today. 29 (2): 43-48.

Mishra A. and Akman I. (2010). Information Technology in Human Resource Management: An Empirical Assessment. Public Personnel Management. 39(3): 243-262.

Power D. (2004). The comparative importance of human resource management practices in the context of business to business (B2B) electronic commerce. Information Technology and People. 17(4): 380-406.

Qureshi T.M. and Hijazi S.T. (2010). Do Human Resource Management Practices Impact on Financial Performance of the Banks?. African Journal of Business Management. 4 (7): 1281-1288.

Rangriz H., Mehrabi J and Azadegan A. (2011). The Impact of Human Resource Information System on Strategic Decisions in Iran. Computer and Information Science. 4(2): 81-87.

Romm C.T., Pliskin N., and Weber Y. (1995). The Relevance of Organizational Culture to the Implementation of Human Resources Information Systems. Asia Pacific Journal of Human Resources. 33(2): 63-80.

Saleem I, Qureshi T.M., Mustafa S, Anwar F. and Hijazi T. (2011). Role of Information and Communicational Technologies in perceived Organizational Performance: An Empirical Evidence from Higher Education Sector of Pakistan. Business Review. 6(1): 8193.

Saleem I., Siddique I., Akmal A., Khan M.S.M., Khan M.U, and Sultan S. (2011). Impact assessment of ISO 9000 series on the organizational performance: Empirical evidence from small and medium enterprise (SME) sector of Pakistan. African Journal of Business Management. 5(26): 10885-10892

Shani A., and Tesone D.V. (2010). Have human resource information systems evolved into internal e-commerce?, Worldwide Hospitality and Tourism Themes. 2(1): 30-48.

Shaw S. (1994). Integrating IT into the Human Resource Management Curriculum Pain or Pleasure?, Education \& Training. 36 (2): 25-30. 
Teo T.S.H., Lim G.S. and Fedric S.A. (2007) . The adoption and diffusion of human resources information systems in Singapore. Asia Pacific Journal of Human Resources. 45(1): 44-62.

Teo T.S.H., Soon L.G. and Fedric S.A. (2001). Adoption and Impact of Human Resource Information Systems. Research and Practice in Human Resource Management. 9(1): 101117.

Tripathi K.P. (2011). A Study of Information Systems in Human Resource Management (HRM). International Journal of Computer Applications. 22 (8): 9-13.

Troshani I., Jerram C. and Hill S.R. (2011). Exploring the public sector adoption of HRIS. Industrial Management \& Data Systems. 111(3): 470 - 488.

Ulrich D., Brockbank W., Yeung A. and Lake D. (2007). Human resource competencies: Responding to increased expectations. Employment Relations. 34(4): 473-496.

Van-der-Linden G. and Parker P. (1998). On paradoxes between human resources management, postmodernism, and HR information systems. Accounting, Management and Information Technology. 8: 265-282.

Wiblen S., Grant D. and Dery K. (2010). Transitioning to a new HRIS: the reshaping of human resources and information technology talent. Journal of Electronic Commerce Research. 11(4): 251-267.

Zhang L. and Wang H. (2006). Intelligent information processing in human resource management: an implementation case in China. Expert Systems. 23 (5): 356-369.

Zhou Y., Zhang Y. and Montoro-Sánchez A. (2011). Utilitarianism or romanticism: the effect of rewards on employees' innovative behaviour. International Journal of Manpower. 32 (1): 81 - 98.

"No fundamental form of culture is infinite in its creative possibilities but is limited....When their creative forces are exhausted and all their limited potential realized, the respective culture and society either becomes petrified and uncreative or else shift to a new form which opens new creative possibilities and new values."

- The Crisis of our Age, P.A. Sorokin, A Dutton Paperback P. 25 